\title{
BMJ Open Plasma pro-atrial natriuretic peptide to indicate fluid balance during cystectomy: a prospective observational study
}

\author{
Kirsten C Rasmussen, ${ }^{1}$ Michael Højskov, ${ }^{1}$ Birgitte Ruhnau, ${ }^{1}$ Lisbeth Salling, ${ }^{2}$
} Tom Pedersen, ${ }^{3}$ Jens $\mathrm{P}$ Goetze, ${ }^{4}$ Niels $\mathrm{H}$ Secher ${ }^{1}$

To cite: Rasmussen KC, Højskov M, Ruhnau B, et al. Plasma pro-atrial natriuretic peptide to indicate fluid balance during cystectomy: a prospective observational study. BMJ Open 2016;6: e010323. doi:10.1136/ bmjopen-2015-010323

- Prepublication history for this paper is available online. To view these files please visit the journal online (http://dx.doi.org/10.1136/ bmjopen-2015-010323).

Received 21 October 2015 Accepted 2 February 2016

CrossMark

\begin{abstract}
${ }^{1}$ Departments of Anaesthesiology,

Rigshospitalet, Copenhagen, Denmark

2Department of Urology,

Rigshospitalet, Copenhagen, Denmark

${ }^{3}$ Center for Head and Orthopaedic Surgery, Rigshospitalet, University of Copenhagen, Copenhagen, Denmark

${ }^{4}$ Department of Clinical Biochemistry, Rigshospitalet, Copenhagen, Denmark
\end{abstract}

Correspondence to Dr Kirsten C Rasmussen; dockcr@yahoo.com

\section{ABSTRACT}

Objectives: During surgery the volume of administered fluid is debated. Pro-atrial natriuretic peptide (proANP) is released by atrial distension, and we evaluated the relationship between changes in proANP associated with perioperative fluid balance.

Design: Prospective observational study.

Setting: One university/tertiary centre.

Participants: The study included patients who underwent radical cystectomy. Plasma for determination of proANP was obtained before surgery, after resection of the bladder, and at the end of surgery for 20 robotic-assisted radical cystectomy (RARC) and 20 open radical cystectomy (ORC) procedures.

Results: The blood loss was 1871 ( $95 \% \mathrm{Cl} 1267$ to 2475) vs $589 \mathrm{~mL}$ (378 to 801) in the ORC and RARC groups ( $p=0.001$ ), respectively, and fluid balance was positive by $1518 \mathrm{~mL}$ (1215 to 1821) during ORC, and by $1858 \mathrm{~mL}$ (1461 to 2255) during RARC ( $\mathrm{p}=0.163)$. Yet, at the end of ORC, plasma proANP was reduced by $23 \%$ ( $14 \%$ to $32 \%, p=0.001$ ), while plasma proANP did not change significantly during RARC. Thus, plasma proANP was associated both with the perioperative blood loss ( $r=-0.475$ (0.632 to -0.101$)$, $p=0.002)$, and with fluid balance ( $r=0.561$ ( 0.302 to 0.740 ), $p=0.001$ ), indicating that a stable plasma proANP required a fluid surplus by $2.4 \mathrm{~L}$ (2.0 to 2.7 ).

Conclusions: There was a correlation between intraoperative haemorrhage and a decrease in plasma proANP and, taking plasma proANP to indicate filling of the heart, about $2.5 \mathrm{~L}$ surplus volume of lactated Ringer's solution appears to maintain cardiac preload during cystectomy.

Trial registration number: EudraCT (2012-00504020), Results.

\section{INTRODUCTION}

During surgery, blood circulation is supported by a crystalloid, but up to $70 \%$ of the administered volume may be lost to the interstitial space even when the circulating blood

\section{Strengths and limitations of this study}

- This prospective study demonstrates a correlation between a decrease in plasma proANP and intraoperative haemorrhage.

- Taking plasma proANP to reflect atrial distension, the study advances the idea that fluid balance is directly related to plasma proANP with about $2.5 \mathrm{~L}$ surplus lactated Ringer solution needed to secure a stable level in patients undergoing major surgery.

- The study was not randomised to the surgical procedures-robotic-assisted radical cystectomy and open radical cystectomy-and not powered to reveal differences in outcome related to changes in plasma proANP.

volume is reduced due to haemorrhage. ${ }^{12}$ Furthermore, a positive postoperative fluid balance may result in gut oedema, contribute to intestinal dysfunction, postoperative complications and extended hospital stay. ${ }^{3} \quad{ }^{4}$ Thus, maintained fluid balance during surgery is important.

Plasma atrial natriuretic peptide (ANP) but not B-type natriuretic peptide $(\mathrm{BNP})^{5}-$ decreases with reduction of the central blood volume during, for example, head-up tilt $^{6}$ or sitting or standing $u^{5}$ as with pressure breathing $^{7}$ indicating that plasma ANP responds to distension of the atria independently of central venous pressure. Compared with ANP, proANP has a longer half-life in plasma, and proANP is therefore applied to evaluate fluid balance. ${ }^{8}$

We use mainly lactated Ringer's (LR) solution to support the circulation during surgery, and considered the volume of LR required to maintain plasma proANP stable during cystectomy. Both patients going through open radical cystectomy (ORC, expected blood loss >1.5 L) and robotic-assisted radical cystectomy (RARC, 
expected blood loss $<0.5 \mathrm{~L}$ ) were included in the evaluation considering that eventual impeded venous return to the heart by abdominal $\mathrm{CO}_{2}$ inflation is compensated by placing the patients in Trendelenburg's position. The aim of the study was to examine the relationship between changes in proANP associated with perioperative fluid balance. We hypothesised that when a blood loss is replaced by LR, it would require a positive volume balance to maintain plasma proANP.

\section{METHODS}

\section{Patients}

The study included patients undergoing resection of the urine bladder due to cancer, was approved by the local ethics committee (H-1-2012-135), and the ORC patients were part of a randomised controlled study (RCT) registered in EudraCT (2012-005040-20). For the 20 ORC patients included consecutively between February 2013 and July $2014,{ }^{9}$ plasma proANP and fluid balance were determined. Furthermore, we analysed a second group of 20 patients undergoing RARC, who were prospectively included in the same period, where plasma proANP and fluid balance were determined as well. Patients selected for ORC and RARC were included in the study to supposedly represent a markedly different blood loss with a similar surgical intervention. ${ }^{10-12}$ The Declaration of Helsinki criteria were followed, and the study was monitored by the Agency for Good Clinical Practice at the University of Copenhagen. ${ }^{13}$ At least $24 \mathrm{~h}$ before surgery written informed consent was obtained from the patients. We excluded patients from this investigatorinitiated, prospective trial if consent was withdrawn. Data were gathered by the investigators and remained confidential throughout the process. The patients were followed-up until discharge, and the authors were involved in every stage of manuscript generation and vouched for the completeness and accuracy of the data. No third party influenced the study design, data analysis or reporting.

\section{Interventions}

Monitoring and fluid administration for the patients during anaesthesia has been published. ${ }^{9}{ }^{14}$ An intravenous line was established, and a catheter placed in the left radial artery and connected to a modified Nexfin monitor (Bmeye BV, Amsterdam, The Netherlands). From the blood pressure recording, heart rate (HR) was determined and stroke volume (SV) estimated by a nonlinear model of arterial impedance using Modelflow technology and cardiac output $(\mathrm{CO})$ calculated. $^{15}$

For induction of anaesthesia, remifentanil infusion was initiated $(0.5 \mu \mathrm{g} / \mathrm{kg} / \mathrm{min})$ and when the patient reported sedation, propofol $(2.0 \mathrm{mg} / \mathrm{kg})$ was administered. Cisatracurium $(0.10-0.15 \mathrm{mg} / \mathrm{kg})$ facilitated oral tracheal intubation, and propofol $(5-10 \mathrm{mg} / \mathrm{kg} / \mathrm{h})$ and remifentanil $(1.75-2.25 \mathrm{mg} / \mathrm{h})$ maintained anaesthesia. With the patient supine, administration of $200 \mathrm{~mL} \mathrm{LR}$ was continued until SV increased by $<10 \%$ according to the 'goal directed fluid therapy' (GDT) paradigm. ${ }^{16}$ Both groups of patients received 5\% human albumin and blood products if considered in need by the anaesthesiologist.

Patients in the ORC group were bent to expose the lower abdominal organs, while RARC patients were in $30^{\circ}$ Trendelenburg's position during resection of the bladder and lymph node exeresis using a da Vinci System (5.0 robotic, Intuitive Surgical Inc., Sunnyvale, California, USA). For RARC patients, bladder reconstruction was established via a lower mini laparotomy with the patient supine. Two surgeons performed the ORC procedures, while two other surgeons performed the RARC procedures.

The HR, mean arterial pressure (MAP), SV and CO were noted after induction of anaesthesia before surgery $\left(\mathrm{T}_{1}\right)$, after resection of the bladder $\left(\mathrm{T}_{2}\right)$, and at the end of anaesthesia $\left(\mathrm{T}_{3}\right)$ before epidural anaesthesia was activated for ORC patients. If systolic pressure fell below $80 \mathrm{~mm} \mathrm{Hg}, 5-10 \mathrm{mg}$ of ephedrine was administered.

Arterial blood was drawn at $\mathrm{T}_{1}$ and $\mathrm{T}_{3}$, that is, before and after abdominal $\mathrm{CO}_{2}$ inflation with the patient supine, and at $T_{2}$ a few minutes after resection of the bladder, when the patient in the ORC group was bent. We analysed plasma for proANP to indicate whether the central blood volume was maintained. ${ }^{17} 18$ The samples were centrifuged for $10 \mathrm{~min}$ at $3.000 \mathrm{rpm}$ at $-5^{\circ} \mathrm{C}$ and stored at $-80^{\circ} \mathrm{C}$ until analysed. Simultaneously, blood was drawn from the central venous catheter for blood gas variables including haemoglobin oxygen saturation $\left(\mathrm{S}_{\mathrm{v}} \mathrm{O}_{2}\right.$, ABL 825, Radiometer, Copenhagen, Denmark). Plasma proANP was measured with an automated method from Thermo-Fisher (the Kryptor Plus platform), where the antibody is directed against epitopes within the mid-region of the precursor (MR-proANP). We validated this method against an immunoassay from our laboratory with excellent performance in non-heart failure patients. ${ }^{19} 20$ Fluid balance was defined as intraoperative fluid infusion (LR, human albumin 5\%, packed red blood cells, fresh frozen plasma) minus blood loss and diuresis.

The outcome variable was postoperative morbidity and length of hospital stay in the ORC and RARC groups. Complications were defined as need for postoperative treatment of cardiopulmonary infections or surgical complications until discharge from hospital.

\section{Statistical analysis}

As an exploratory study of the plasma proANP response to surgery, no power analysis was performed. We used two-sided or unadjusted $\chi^{2}$ tests, $\mathrm{t}$ test and Fisher's exact test for continuous and dichotomous variables, respectively. Results are presented as mean (SD) or median, as appropriate, and the $95 \%$ CI is provided. Test for differences used the non-parametric Spearman's test, $\chi^{2}$ test for categorical data, and analysis of variance or Mann-Whitney $\mathrm{U}$ test and Wilcoxon signed-rank test for 
continuous data when appropriate. For intraoperative bleeding, multivariate logistic regression analysis was performed to define whether plasma proANP was independently associated with intraoperative bleeding with $1.5 \mathrm{~L}$ considered to represent an approximately $30 \%$ loss of blood volume and, thereby, potentially affecting blood pressure. ${ }^{21}$ Statistical analyses were performed using SPSS V.20.0 (SPSS Inc, Chicago, Illinois, USA).

\section{RESULTS}

There was no significant intergroup difference in baseline data including preoperative diseases between the two groups of patients (table 1). After induction of anaesthesia, $59 \%$ of the participants were normovolaemic according to the GDT criteria.

\section{Haemorrhage, fluid administration and haemodynamics}

The intraoperative lost blood was $1871 \mathrm{~mL}$ (CI 1267 to 2475) during ORC vs $589 \mathrm{~mL}$ (CI 378 to 801) in the RARC group $(p=0.0001)$. Significant haemorrhage was also more frequent during ORC as $45 \%$ of these patients lost more than $1500 \mathrm{~mL}$ of blood versus only $5 \%$ in the RARC group, $\mathrm{p}=0.008$ (table 1 ). Table 2 presents administration of intravenous fluids: total fluid infusion was by 3580 (2989 to 4171) vs $2762 \mathrm{~mL}$ (2266 to 3258) $(\mathrm{p}=0.033)$ in the ORC and RARC groups, respectively. The net fluid balance was positive in both groups: by $1518 \mathrm{~mL}$ (1215 to 1821) during ORC and by $1858 \mathrm{~mL}$ (1461 to 2255) during RARC ( $\mathrm{p}=0.163)$. Accordingly, haemoglobin was more reduced (by 13\%) during ORC than during RARC (by 7\%, $\mathrm{p}=0.001$ ). Seven patients in the ORC group were provided with transfusion of blood versus one patient during RARC, resulting in administration of 325 (73 to 577 ) vs 61 ( 0 to 189 ) $\mathrm{mL}$ packed red blood cells $(\mathrm{p}=0.058)$, respectively, with no marked differences between observations at $\mathrm{T}_{2}$ and $\mathrm{T}_{3}$.

The CO increased almost $50 \%$ during RARC (from $4.6 \pm 1.2$ to $6.3 \pm 1.5 \mathrm{~L} / \mathrm{min}) \quad(\mathrm{p}=0.001)$, and was higher than in ORC patients $(\mathrm{p}=0.001)$; and also $\mathrm{S}_{\mathrm{v}} \mathrm{O}_{2}$ was higher during RARC $(82 \pm 5 \%$ vs $73 \pm 6 \%, \mathrm{p}=0.001)$. The MAP increased by approximately $10 \%$ (from $63 \pm 15$ to $69 \pm 14 \mathrm{~mm} \mathrm{Hg}, \mathrm{p}<0.05$ ) in both groups of patients, and without difference in the total dose of administered ephedrine. In the two groups of patients, there was a similar increase in HR (from $63 \pm 13$ to $81 \pm 14 \mathrm{bpm}$ in RARC patients, and from $63 \pm 12$ to $76 \pm 16 \mathrm{bpm}$ in ORC patients).

\section{Plasma proANP}

During ORC, plasma proANP was reduced by $23 \%$ (14\% to $32 \%, \mathrm{p}=0.001$ ), but remained unchanged during RARC (table 3). Changes in plasma proANP were related to the blood loss $(\mathrm{r}=-0.475 \quad(-0.632$ to -0.101$)$, $\mathrm{p}=0.002)$ (figure $1 \mathrm{~A})$ and to fluid balance $(\mathrm{r}=0.561$ (0.302 to 0.740$), \mathrm{p}=0.001$ ) (figure $1 \mathrm{~B}$ ). Thus, a stable plasma proANP during surgery appeared to require a fluid surplus of $2.4 \mathrm{~L}$ (2.0 to 2.7). By multiple regression analysis, only plasma proANP was independently associated with the perioperative blood loss (table 4).

\section{Postoperative observations}

There was no significant difference in postoperative complications between the surgical groups, that is, four patients in the ORC and the RARC groups were treated due to postoperative complications. The length of hospital stays were similar, 7 days (6-92) in the ORC group vs 7 days (5-21) in the RARC group ( $p=0.33$ ).

\section{DISCUSSION}

Plasma proANP is released in response to atrial distension independently of central venous pressure, and we considered an increase to reflect intravascular volume expansion and, conversely, a reduction to indicate a reduced central blood volume. For patients going through ORC and RARC, plasma proANP was related to

\begin{tabular}{|c|c|c|c|c|}
\hline Variable & Overall $(n=40)$ & RARC $(n=20)$ & ORC $(n=20)$ & p Value \\
\hline Age, years & $66.6(7.7)$ & $64.8(8.5)$ & $68.6(6.5)$ & 0.12 \\
\hline Male sex & $32(40)$ & $18(90)$ & $14(70)$ & 0.24 \\
\hline $\mathrm{BMI}, \mathrm{kg} / \mathrm{m}^{2}$ & $25.5(5.5)$ & $25.8(3.3)$ & $25.1(7.1)$ & 0.70 \\
\hline ASA classification, I and II/III & $32 / 8$ & $17 / 3$ & $15 / 5$ & 0.69 \\
\hline Cardiopulmonary disease & $23(58)$ & $11(55)$ & $12(60)$ & 1.00 \\
\hline Hypertension & $16(40)$ & $9(45)$ & $7(35)$ & 0.37 \\
\hline Chronic heart failure & $2(5)$ & $1(5)$ & $1(5)$ & 0.76 \\
\hline Diabetes & $5(13)$ & $1(5)$ & $4(20)$ & 0.17 \\
\hline Smokers (current and former) & $32(80)$ & 17 (85) & $15(75)$ & 0.70 \\
\hline Duration of surgery, min & $255(82)$ & $325(37)$ & $184(45)$ & 0.001 \\
\hline Ephedrine, mg & $32.8(17)$ & $31.0(19)$ & $34.6(16)$ & 0.03 \\
\hline Blood loss >1500 mL & $10(25)$ & $1(5)$ & $9(45)$ & 0.008 \\
\hline Blood administration & $8(20)$ & $1(5)$ & $7(35)$ & 0.044 \\
\hline
\end{tabular}


Table 2 Fluid administration and balance during anaesthesia

\begin{tabular}{|c|c|c|c|c|}
\hline Variable & Overall $(n=40)$ & RARC (n=20) & ORC $(n=20)$ & p Value \\
\hline Total fluid infusion $(\mathrm{mL})^{\star}$ & 3171 (2780 to 3563 ) & 2762 (2266 to 3258 ) & 3580 (2988 to 4171$)$ & 0.033 \\
\hline Ringer's solution (mL) & 2393 (2186 to 2599$)$ & 2336 (1994 to 2677 ) & 2450 (2186 to 2714$)$ & 0.58 \\
\hline PRBC $(\mathrm{mL})$ & 193 (52 to 334) & 61 (0 to 189) & 325 (73 to 576$)$ & 0.058 \\
\hline Albumin (mL) & 319 (197 to 440$)$ & 188 (51 to 323$)$ & 450 (254 to 646$)$ & 0.027 \\
\hline Total fluid loss $(\mathrm{mL}) \dagger$ & 1486 (1126 to 1847$)$ & 905 (665 to 1145$)$ & 2068 (1470 to 2667 ) & 0.001 \\
\hline Diuresis $(\mathrm{mL})$ & 260 (202 to 319$)$ & 321 (228 to 413 ) & 201 (132 to 270$)$ & 0.037 \\
\hline Blood loss (mL) $\ddagger$ & 1230 (861 to 1599$)$ & 589 (378 to 801$)$ & 1871 (1267 to 2475$)$ & 0.001 \\
\hline Total fluid balance (mL) & 1688 (1444 to 1933$)$ & 1858 (1461 to 2255$)$ & $1518(1215$ to 1821$)$ & 0.163 \\
\hline
\end{tabular}

Values for fluid balance are expressed as means with $95 \% \mathrm{Cl}$. Also $\mathrm{p}$ value determined by ANOVA test compared differences in fluid volume between the RARC and ORC groups are given.

${ }^{*}$ Fluid administered during anaesthesia.

†Blood and urine lost during anaesthesia.

$\ddagger$ Blood loss during anaesthesia and fluid balance=fluid infusion-fluid lost during anaesthesia.

ANOVA, analysis of variance; ORC, open radical cystectomy; PRBC, packed red blood cells; RARC, robotic-assisted radical cystectomy.

the volume load at the end of surgery and a stable value was established with a $2.4 \mathrm{~L}(2.0-2.7)$ surplus.

Plasma proANP correlated not only to volume balance, it also demonstrated a negative correlation to the loss of blood. Thus, with a blood loss by approximately $300 \mathrm{~mL}$, there was no change in plasma proANP, with a $2000 \mathrm{~mL}$ positive fluid balance during surgery (figure 1). On the contrary, with a $3300 \mathrm{~mL}$ blood loss, plasma proANP decreased by about $40 \%$ despite a $500 \mathrm{~mL}$ positive volume balance. Perioperative haemorrhage and need for transfusion is larger during ORC compared with $\mathrm{RARC}^{10-12}$ as confirmed here, and only ORC patients demonstrated a significant decrease in plasma proANP.

We optimised the intravascular volume before surgery according to GDT criteria, ${ }^{16}$ and aimed to maintain a maximal SV, $\mathrm{CO}$ and $\mathrm{S}_{\mathrm{v}} \mathrm{O}_{2}$ throughout surgery although the late evaluation was not a protocol. Yet, for the RARC patients, CO increased in Trendelenburg's position indicating a central blood volume deficit at that time. ${ }^{22}$ Furthermore, $\mathrm{CO}$ and $\mathrm{S}_{\mathrm{v}} \mathrm{O}_{2}$ were larger for RARC than for ORC patients, and although HR did not differ between the two groups of patients, the other cardiovascular variables supported that the ORC patients were

\begin{tabular}{|c|c|c|c|c|}
\hline Variable & $\begin{array}{l}\text { All } \\
(n=40)\end{array}$ & $\begin{array}{l}\text { RARC } \\
(n=20)\end{array}$ & $\begin{array}{l}\text { ORC } \\
(n=20)\end{array}$ & $\begin{array}{l}\text { p } \\
\text { Value* }\end{array}$ \\
\hline \multicolumn{5}{|c|}{ ProANP (pmol/L) } \\
\hline $\mathrm{T}_{1}$ & $130(66)$ & 106 (37) & 153 (79) & 0.094 \\
\hline $\mathrm{T}_{2}$ & $114 \dagger(49)$ & $108(40)$ & $120 \ddagger(60)$ & 0.787 \\
\hline $\mathrm{T}_{3}$ & $107 \ddagger(47)$ & $104(33)$ & $115 \ddagger(59)$ & 0.646 \\
\hline
\end{tabular}

$\mathrm{T}_{1}=$ before start of surgery; $\mathrm{T}_{2}=$ after resection of the urinary bladder; $T_{3}=a t$ the end of anaesthesia. Data are mean (SD), $p$ value determined by univariate analysis.

${ }^{*}$ t Test compared differences in hormones between the RARC and ORC group.

$\dagger p<0.01$ difference from anaesthesia induction within the group. $\neq p<0.001$ difference from anaesthesia induction within the group (Wilcoxon signed-rank test).

ORC, open radical cystectomy; proANP; pro-atrial natriuretic peptide; RARC, robotic-assisted radical cystectomy. hypovolaemic. That was the case although the fluid balance at the end of surgery was positive by $1.9 \mathrm{~L}$ for ORC patients and similar (1.5 L) for RARC patients.
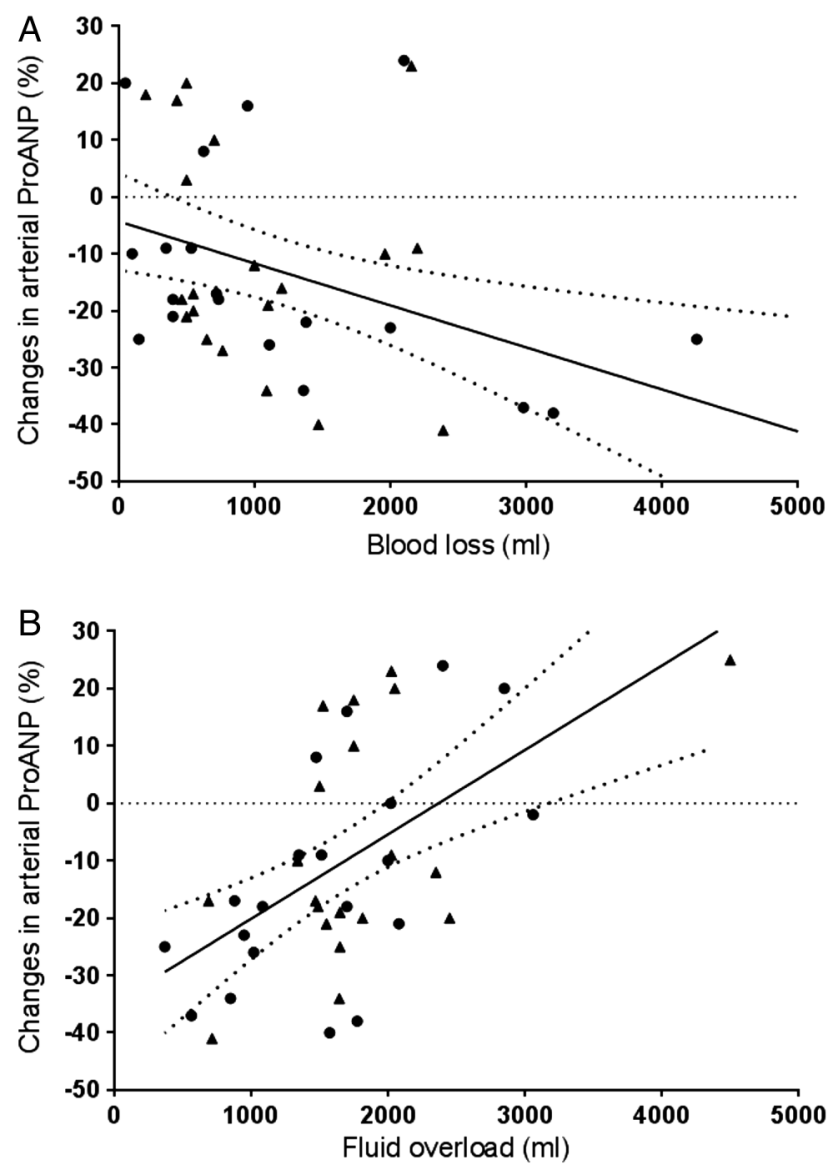

Figure 1 Pro-atrial natriuretic peptide ProANP in relation to intraoperative blood loss and fluid balance. Change in plasma proANP from start (T1) to end of anaesthesia (T3) in patients during robotic-assisted (RARC) (black angle) or open radical cystectomy (ORC) (black circle), $r=-0.475(95 \% \mathrm{Cl}-0.632$ to $-0.101), p=0.002(A)$ and $r=0.561$ (0.302 to 0.740$), p=0.001$ (B). Regression lines shown with $95 \% \mathrm{Cl}$. Horizontal broken lines indicate no change in plasma proANP. 
Table 4 Multiple logistic regression analysis of changes in plasma proANP ( $<80 \%$ vs $\geq 80 \%$ of T1 value) during anaesthesia in relation to blood loss and fluid excess

\begin{tabular}{llllll}
\hline Variable & $\begin{array}{l}\text { Regression } \\
\text { coefficient }(\boldsymbol{\beta})\end{array}$ & SE & p Value & OR $\left(\mathbf{e}^{\boldsymbol{\beta}}\right)$ & $\mathbf{9 5 \%} \mathbf{C l}$ \\
\hline ProANP & & & & & \\
$\quad$ Blood loss $>1500$ vs $<1500 \mathrm{~mL}$ & -1.84 & 0.86 & 0.034 & 0.16 & 0.03 to 0.87 \\
Fluid balance $<2000 \mathrm{vs} \geq 2000 \mathrm{~mL}$ & 1.69 & 1.21 & 0.163 & 5.43 & 0.50 to 58.59 \\
$\quad$ Constant & -1.22 & 1.14 & 0.286 & &
\end{tabular}

It should be considered how fluid balance is estimated. There may be a 1:5 volume ratio between the intravascular and interstitial fluid space $^{2}$ and a separate calculation may be conducted for colloids and crystalloids. If only $25 \%$ of the administered $2762 \mathrm{~mL}$ of LR remained within the plasma space $(690 \mathrm{~mL})$ together with 5\% human albumin and packed red blood cells, the intravascular fluid balance is, on average, positive by $30 \mathrm{~mL}$ for the RARC patients. For the ORC patients, a similar calculated intravascular fluid balance becomes negative by $400 \mathrm{~mL}$. Thus, a calculation of fluid balance based on distinction between colloids and LR, supports that ORC patients were exposed to an intravascular volume deficit. Fluid administration was standardised with patients receiving LR and substitution of the blood loss with packed red blood cells and, eventually, human albumin. ${ }^{23}$ Thus, according to plasma proANP, established intravascular volume deficit-despite a positive volume balance-reflects distribution of LR to the extravascular space.

Plasma proANP indicates a volume surplus for patients in septic shock. ${ }^{24}$ The largest values for plasma proANP were for patients with the highest Acute Physiology and Chronic Health Evaluation score and for non-survivors. In order to discriminate between survivors and nonsurvivors, the proANP cut-off concentration was $221 \mathrm{pmol} / \mathrm{L}$ (with a high sensitivity, but a low specificity; likelihood ratio 2.0). In the present study, plasma proANP was only about half that level, and decreased further for the ORC patients.

The participants were not randomised to the two surgical procedures, however, the history of the patients was similar. Also, the study was not considered to reveal differences in postoperative outcome-neither related to changes in plasma proANP, nor between the surgical methods. Other means of evaluating cardiac filling during surgery, including, for example, echocardiography or a determination of blood volume, may be required to generalise the present findings, and the evaluation could be extended to include frequent evaluation of plasma proANP during surgery. However, values determined during surgery $\left(T_{2}\right)$ were not deviating from those obtained at $\mathrm{T}_{3}$ and, therefore, not detailed. We could have recorded central venous pressure, but plasma ANP relates to atrial stretch rather than to atrial pressure. ${ }^{7}$

A critical consideration for this study is how fluid balance is estimated. If a separate calculation is made for colloids (blood and albumin) and crystalloids, the ORC patients had a colloid deficit of 1518 vs $422 \mathrm{~mL}$ for the RARC patients, but the two groups of patients were supported by an almost identical crystalloid surplus (by 1771 vs $1478 \mathrm{~mL}$, table 2). The calculation, thereby, supports that the volume load was small for the ORC patients, but we admit that a determination of blood volume or the central blood volume was not established.

Taking that (pro)ANP reflects atrial distension, we advance the idea that fluid balance during surgery can be evaluated in relation to cardiac preload. We demonstrate a correlation between a decrease in plasma proANP and haemorrhage, while fluid balance based mainly on LR was directly related to plasma proANP with about 2.5 L surplus volume needed to secure a stable level in patients undergoing radical cystectomy. In consequence, it remains to be established whether the clinical outcome would be improved by administration of some colloid rather than base fluid support on LR only.

Contributors KCR, BR, JPG and NHS contributed to the conception and design of the work; $\mathrm{KCR}, \mathrm{MH}$ and $\mathrm{BR}$ were responsible for perioperative management and recording clinical characteristics; KCR, MH, BR, LS, TP, JPG and NHS were involved in the analysis and interpretation of the data; KCR, $\mathrm{MH}, \mathrm{BR}, \mathrm{LS}, \mathrm{TP}, \mathrm{JPG}$ and NHS were involved in the drafting of the manuscript and its revision for important intellectual content, and gave final approval for the manuscript.

Funding This work was supported by grants from AP Møller's Fond, Copenhagen, Denmark; The Augustinus Fond, Copenhagen, Denmark; Aase and Ejnar Danielsen's Fond, Lyngby, Denmark.

Competing interests None declared.

Patient consent Obtained.

Ethics approval The ethic committee in the capital region of Denmark (H-1-2012-135).

Provenance and peer review Not commissioned; externally peer reviewed.

Data sharing statement Additional data can be accessed via the Dryad data repository at http://datadryad.org/ with the doi:10.5061/dryad.56np2.

Open Access This is an Open Access article distributed in accordance with the Creative Commons Attribution Non Commercial (CC BY-NC 4.0) license, which permits others to distribute, remix, adapt, build upon this work noncommercially, and license their derivative works on different terms, provided the original work is properly cited and the use is non-commercial. See: http:// creativecommons.org/licenses/by-nc/4.0/

\section{REFERENCES}

1. Zaar M, Lauritzen B, Secher $\mathrm{NH}$, et al. Initial administration of hydroxyethyl starch vs lactated Ringer after liver trauma in the pig. Br J Anaesth 2009;102:221-6. 
2. lijima $T$, Brandstrup $B$, Rodhe $P$, et al The maintenance and monitoring of perioperative blood volume. Perioper Med 2013;2:9.

3. Bundgaard-Nielsen M, Secher NH, Kehlet H. 'Liberal' vs. 'restrictive' perioperative fluid therapy-a critical assessment of the evidence. Acta Anaesthesiol Scand 2009;53:843-51.

4. Doherty M, Buggy DJ. Intraoperative fluids: how much is too much? Br J Anaesth 2012:109:69-79.

5. Vogelsang TW, Yoshiga CC, Højgaard M, et al. The plasma atrial natriuretic peptide response to arm and leg exercise in humans: effect of posture. Exp Physiol 2006;9:765-71.

6. Matzen S, Knigge U, Schütten $\mathrm{HJ}$, et al. Atrial natriuretic peptide during head-up tilt induced hypovolaemic shock in man. Acta Physiol Scand 1990:140:161-6.

7. Schütten HJ, Kamp-Jensen M, Nielsen SL, et al. Inverse relation between central venous pressure and the plasma concentration of atrial natriuretic peptide during positive-pressure breathing. Acta Physiol Scand 1990;139:389-90.

8. Goetze JP, Hansen LH, Terzic D, et al. Atrial natriuretic peptides in plasma. Clin Chem Acta 2015;443:25-8.

9. Rasmussen KC, Hoejskov M, Johansson PI, et al. Coagulation competence for predicting perioperative hemorrhage in patients treated with lactated Ringer's vs. Dextran - a randomized controlled trial. BMC Anesthesiol 2015;15:178. doi:10.1186/s12871-015-0162-1

10. Knox ML, El-Galley R, Busby JE. Robotic versus open radical cystectomy: identification of patients who benefit from the robotic approach. J Endourol 2013;27:40-4.

11. Nix J, Smith A, Kurpad R, et al. Prospective randomized controlled trial of robotic versus open radical cystectomy for bladder cancer: Perioperative and pathologic results. Eur Urol 2010;57:196-201.

12. Kauffman $\mathrm{EC}, \mathrm{Ng} \mathrm{CK}$, Lee MM, et al. Critical analysis of complications after robotic-assisted radical cystectomy with identification of preoperative and operative risk factors. BJU Int 2010;105:520-7.

13. ICH Steering Committee. International Conference on Harmonisation of Technical Requirements for Registration of Pharmaceuticals for Human Use: ICH Harmonised Tripartite Guideline for Good Clinical Practice. 3rd edn. London, UK: Brookwood Med Pub, 1998.
14. Rasmussen KC, Johansson PI, Højskov M, et al. Hydroxyethyl starch reduces coagulation competence and increases blood loss during major surgery: results from a randomized controlled trial. Ann Surg 2014;259:249-54.

15. de Vaal JB, de Wilde RBP, van den Berg PCM, et al. Less invasive determination of cardiac output from the arterial pressure by aortic diameter-calibrated pulse contour. $\mathrm{Br} \mathrm{J}$ Anaesth 2005;95:326-31.

16. Bundgaard-Nielsen M, Jørgensen $\mathrm{CC}$, Secher NH, et al. Functional intravascular volume deficit in patients before surgery. Acta Anaesthesiol Scand 2010;54:464-9.

17. Sander-Jensen $\mathrm{K}$, Secher $\mathrm{NH}$, Astrup A, et al. Hypotension induced by passive head-up tilt: endocrine and circulatory mechanisms. $A m$ J Physiol 1986;251:R742-8.

18. Sander-Jensen $\mathrm{K}$, Secher $\mathrm{NH}$, Bie $\mathrm{P}$, et al. Vagal slowing of the heart during haemorrhage: observations from 20 consecutive hypotensive patients. BMJ 1986;292:364-6.

19. Hunter I, Rehfeld JF, Goetze JP. Measurement of the total proANP product in mammals by processing independent analysis. $J$ Immunol Meth 2011;370:104-10.

20. Hunter I, Alehagen U, Dahlström U, et al. N-terminal pro-atrial natriuretic peptide measurement in plasma suggests covalent modification. Clin Chem 2011;57:1327-30.

21. Hahn RG. Crystalloid and colloid fluids. In: Hahn RG, ed. Clinical fluid therapy in the perioperative setting. Cambridge, NY: Cambridge University Press, 2011:66-76.

22. Harms, MPM, van Lieshout JJ, Jenstrup M, et al. Postural effects on cardiac output and mixed venous oxygen saturation in humans. Exp Physiol 2003;88:611-16.

23. Corcoran T, Rhodes JEJ, Clarke S, et al. Perioperative fluid management strategies in major surgery: a stratified meta-analysis. Anaesth Analg 2012;114:640-51.

24. Lipinska-Gediga M, Mierzchala M, Durek G. Pro-atrial natriuretic peptide (pro-ANP) level in patients with severe sepsis and septic shock: prognostic and diagnostic significance. Infection 2012;40:303-9. 